\title{
Características dos produtores e propriedades de bubalinos na baixada Maranhense
}

Luciana de Paula Costa Lima ${ }^{1}$, Elaine Farias Dias ${ }^{1}$, Diego Carvalho Viana ${ }^{2 *}$, Amilton Cesar dos Santos', Guilherme Augusto Silvestre Ferreira ${ }^{2}$, Fernando de Andrade Souza $^{4}$, Leônidas Antônio Chow Castillo ${ }^{4}$, Abisai de Oliveira Sousa ${ }^{4}$

${ }^{1}$ Discente de Zootecnia da Universidade Estadual do Maranhão (UEMA), São Luís, Brasil.

${ }^{2}$ Pós-graduando do Programa de Anatomia dos Animais Domésticos e Silvestres da Faculdade de Medicina Veterinária e Zootecnia de São Paulo (FMVZ/USP). Av. Prof. Dr. Orlando Marques de Paiva, 87, Cidade Universitária - CEP 05508 270, São Paulo-SP.

${ }^{3}$ Acadêmico do curso de Ciências Biológicas, Universidade São Judas Tadeu - Campus Mooca (USJT)

${ }^{4}$ Departamento de Reprodução Animal, Curso de Medicina Veterinária, Universidade Estadual do Maranhão (UEMA), Cidade Universitária Paulo VI, Tirirical, São Luís, MA, 65054-970, Brasil.

*Autor para correspondência, E-mail: dieob@bol.com.br

RESUMO. Esta pesquisa teve o objetivo de levantar as informações sobre as características dos produtores e fazendas de búfalos do município de Viana no Estado do Maranhão. A metodologia utilizada foi aplicar um questionário-entrevista numa amostra de aproximadamente $15 \%$ dos produtores e em seguida quantificar os valores informados. Verificou-se que os produtores dessa região são em sua maioria do gênero masculino (90\%), e $80 \%$ criam em suas próprias terras, sendo que $20 \%$ são parceiros de proprietários de terras por não terem local para desenvolverem a pecuária. Aproximadamente $46 \%$ têm a criação de búfalos como uma importante renda familiar. Conclui-se que os produtores encontram dificuldades para ampliar as atividades por falta de orientação técnica. Constata-se que estas carências promovem dificuldades para o desenvolvimento da bubalinocultura no estado.

Palavras chave: Búfalo, Maranhão, Viana-MA

\section{Characteristics of producersand farms of buffaloes at the baixada Maranhense}

\begin{abstract}
This research aimed to collect information on characteristicsof producers and farms of buffalo, the municipality of Viana, Maranhão. For this purpose, a questionnaire-interview for approximately $15 \%$ of the producers was applied. Then the reported values were quantified. It was found that farmers in this region are mostly male (90\%), and $80 \%$ own their own land, while $20 \%$ are partners with land owners. Approximately $46 \%$ has buffalo breeding as an important family income. It is concluded that producers have difficult to extend the activities due to lack of technical guidance. It was found that these deficiencies difficult to promote the development of thebuffalos production in this state.
\end{abstract}

Keywords: Buffalo, Maranhão, Viana-MA

\section{Introdução}

A bubalinocultura brasileira vem apresentando elevado crescimento nas últimas décadas, evidenciado pelo aumento populacional desses animais em diversas propriedades e regiões, destinados tanto para produção de leite e abate quanto para comercialização de matrizes e reprodutores (Rodrigues et al., 2008). Estão presentes nos campos inundáveis que caracterizam a Baixada Maranhense e estes são ambientes constituídos por lagos temporários, marginais e permanentes. Durante os seis meses de estiagem (julho-dezembro) nesses campos ocorremconsiderável produção de gramíneas nativas, durante a diminuição do nível das águas, o que propicia alimento para estes animais pouco seletivos (Costa Neto, 2002). As atividades econômicas de subsistência da região apoiam-se no extrativismo vegetal, caça predatória, pesca e pecuária (Bernardi, 2005). 
Os campos em sua maioria são de domínio popular, partilhados por vários trabalhadores envolvidos na atividade pecuária (bovinos, equinos, suínos e bubalinos) (Atlas, 2002). O búfalo é um animal dócil, de fácil manejo e lucrativo, pois em uma mesma criação há várias formas de exploração comercial, sendo considerada como principais a produção de carne, leite e trabalho, razão pela qual também é descrito como animal de tripla aptidão.

Segundo Andrade et al. (2005) quatro raças são criadas no Brasil: Murrah, Jafarabadi e Mediterrânea do gênero Bubalus bubalise o Carabao do gênero Bubalus kerebau com baixa densidade.

A pecuária bubalina na Baixada Maranhense foi iniciada para a manutenção familiar dos pequenos e médios produtores devido sua conhecida rusticidade e desde sua instalação pouco receberam de orientação técnica e assim é hoje uma atividade extensiva de subsistência.

Estetrabalho visou realizar a coleta de informações sobre a exploração da pecuária bubalina no Município de Viana na Baixada Maranhense, no intuito de utilizá-los em estudosque promovam melhorias no manejo com vistas à melhor aproveitamento e comercialização dos seus produtos possibilitando maior renda aos criadores.

\section{Material e Métodos}

\section{Local de estudo}

Este estudo foi realizado na Baixada Maranhense, no Município de Viana que possui aproximadamente 49.452 habitantes, e população bubalina de aproximadamente 25.000 cabeças.

\section{Coleta de dados}

A pesquisa é do tipo quali-quantitativa e de natureza descritiva. As estrevistas foram realizadas nos meses de março e abril de 2013, com os criadores de bufalos, utilizando-se questionário técnico utilizado pela Agência de Defesa Animal do Estado do Maranhão (AGED) foram selecionados 50 criadores cadastrados. Estes questionários abordaram perguntas sobre caracterização do produtor e de sua família, da propriedade, do rebanho e das atividades realizadasno empreendimento (Malhotra, 2003). Este município foi escolhido por ter o maior efetivo estadual, aproximadamente 30\% (16.000 cabeças bubalinas) do plantel maranhense, segundo último censo agropecuário (IBGE, 2010), o Estado do Maranhão somava um efetivo de 52.848 cabeças. Os dados foram organizados em frequência.

\section{Resultados e Discussão}

A amostra foi composta por $90 \%$ de indivíduos do sexo masculino e $10 \%$ do sexo feminino. Destes entrevistados, a grande maioria $80 \%$ apresentava-se como proprietários de terras em que criavam seus animais e os demais $20 \%$ não possuíam terras de sorte que criavam em forma de parceria, em sua grande maioria com parentes próximos ou amigos. Com relação à procedência do produtor, observou-se que $12 \%$ dos entrevistados eram oriundos de outros municípios e $88 \%$ eram nascidos no município em que o estudo foi realizado. A maioria dos bubalinocultores $(54 \%)$ pratica outras atividades de produção para a composição da renda familiar, os demais $46 \%$ retiram da produção bubalina sua renda principal (Tabela 1). Diferentedas regiões da Baixadas Litorâneas do Norte Fluminense em que a grande maioria das propriedades não possui a bubalinocultura como principal criação, apresentando menos de 150 animais por empreendimento e sendo voltados para produção de carnee, em geral não possuem orientação técnica (Quirino, 2004; 2005).

Tabela 1. Bubalinocultores segundo sexo, procedência, posse da terra e atividade produtiva no município de Viana na Baixada Maranhense (MA) 2013

\begin{tabular}{llccc}
\hline \multirow{2}{*}{ Gênero } & & $\%$ & $\mathrm{~N}^{\circ}$ de entrevistados & $f$ \\
& Masculino & 90 & 45 & 0.90 \\
\multirow{2}{*}{ Procedência } & Feminino & 10 & 5 & 0.10 \\
\hline \multirow{2}{*}{ Posse da terra } & Próprio município & 88 & 44 & 0.88 \\
& Outro município & 12 & 6 & 0.12 \\
\hline \multirow{2}{*}{ Atividade produtiva } & Proprietário & 79 & 40 & 0.80 \\
& Parceria & 21 & 10 & 0.20 \\
\hline
\end{tabular}


A maioria dos bubalinocultores (88\%) possuíam atividade financiada custeada incluído nesta categoria o crédito bancário, entretanto somente $12 \%$ faziam investimentos na criação de bubalinos (Tabela 2.). Em relação ao critério de terem algum equipamento em conjunto com vizinho, na sua totalidade (100\%), não exerciam essa prática. Cerca de $74 \%$ não trabalhavam com crédito bancário, entretanto $26 \%$ trabalhavam com todas as possíveis linhas de créditos existentes.

Os produtores de bubalinos informaram que em relação ao acesso à propriedade no período seco a maioria (42\%) tem acesso regular, enquanto $20 \%$ deles têm acesso ótimo, $28 \%$ bom e $10 \%$ ruim. No período chuvoso o acesso se dá como bom em $32 \%$ dos casos, sendo ótimo para $8 \%$ deles e de qualidade regular para $30 \%$ e ruim para $30 \%$ deles, como demonstrado na Tabela 3. Estes dados contribuem para compreender a mesma dificuldade encontrada por criadores na Ilha de Marajó, Estado do Pará, em que as condições físicas são relatadas como um das principaisadversidades na produção bubalina (Barbosa, 2005).

Tabela 2. Distribuição percentual da criação bubalina em relação aos recursos dos entrevistados no município Viana - MA

\begin{tabular}{lccc}
\hline Atividade Financiada & $\%$ & $\mathrm{~N}^{\circ}$ de entrevistados & $f$ \\
\hline Custeio & 88 & 44 & 0,88 \\
Investimento & 12 & 6 & 0,12 \\
\hline
\end{tabular}

Tabela 3. Distribuição percentual da frequência dos dados de acesso à propriedade dos bubalinocultores entrevistados no município Viana - MA

\begin{tabular}{lccc|ccc}
\hline \multirow{2}{*}{$\begin{array}{l}\text { Acesso à } \\
\text { Propriedade }\end{array}$} & $\%$ & $\mathrm{~N}^{\circ}$ de entrevistados & $f$ & $\%$ & $\mathrm{~N}^{\circ}$ de entrevistados & $f$ \\
\hline ńtimo & 20 & 10 & 0.20 & 8 & 4 & 0.08 \\
Bom & 28 & 14 & 0.28 & 32 & 16 & 0.32 \\
Regular & 42 & 21 & 0.42 & 30 & 15 & 0.30 \\
Ruim & 10 & 5 & 0.10 & 30 & 15 & 0.30 \\
\hline
\end{tabular}

\section{Considerações finais}

Constatou-se que os produtores da Baixada Maranhenseencontram dificuldades diversas para tornar a bubalinocultura a principal renda familiar, haja vista a que maioria dos entrevistados possui terra própria, no entanto, as dificuldades para utilizarem o crédito rural ainda é um fator limitador. Esses fatos constituem empecilhos para o desenvolvimento da bubalinocultura no estado do Maranhão.

\section{Referências Bibliográficas}

Atlas do Maranhão. Laboratório de geoprocessamento - UEMA. São Luís: GEPLAN, p. 44, 2002.

Andrade, V. J. \& Garcia, S. K. 2005. Padrões raciais e registro de bubalinos. Revista Brasileira de Reprodução Animal, 29, 39-45.
Barbosa, N.G.S. 2005. Bubalinocultura no Estado do Pará. Revista Brasileira de Reprodução Animal, 29, 34-38.

Bernardi, C.C. 2005. Conflitos sócio-ambientais decorrentes da bubalinocultura em territórios pesqueiros artesanais: o caso Olinda Nova do Maranhão. Brasília, 217p.

Costa Neto, J.P. 2002. Limnologia de três ecossistemas aquáticos característicos da Baixada Maranhense. Boletim do Laboratório de Hidrobiologia, 14/15,19-38.

IBGE. Censo Demográfico 2010. Disponível em: http://www.ibge.gov.br. Acesso em: 20 Dez. 2013.

Malhotra, N.K. 2005. Pesquisa de marketing: uma orientação aplicada.Revista Brasileira de Reprodução Animal,29,39-45.

Quirino, C. R.: Madella-Oliveira, A. F. \& Pacheco, A. 2004. Descrição das propriedades 
criadoras de búfalos no Norte-Noroeste Fluminense. In: $9^{\circ}$ Encontro de Iniciação Científica, $4^{\mathrm{a}}$ Mostra de Pós-Graduação e $2^{\mathrm{a}}$ Mostra de Extensão. Anais- UENF.

Quirino, C. R.; Madella-Oliveira, A. F.; Pacheco, A.; Souza, S. L. G.; Neves, G. D., Monteiro, L. P. \& Olmo, J. M. O. 2005. Capacitação e assistência aos criadores de búfalos, em relação ao manejo e à produção ecológica de carne e leite, na região Norte e Noroeste Fluminense - PROBUF. Anais do ZOOTEC Campo Grande-MS.

Rodrigues, C. F. C.; Iapichini, A. M.; Liserre, K. B.; Souza, C.; Fachini, R. H. \& Reichert.
2008. Oportunidades e desafios da bubalinocultura familiar da região sudoeste paulista. Revista Tecnologia e Inovação Agropecuária,23, 100-109.

Recebido em Junho 21, 2015

Aceito em Agosto 4, 2015

License information: This is an open-access article distributed under the terms of the Creative Commons Attribution License, which permits unrestricted use, distribution, and reproduction in any medium, provided the original work is properly cited. 